\title{
AS TECNOLOGIAS DA INFORMAÇÃO E COMUNICAÇÃO E A GESTÃO DO CONHECIMENTO COMO APOIO AO GERENCIAMENTO DAS COMUNICAÇÕES EM PROJETOS
}

\section{THE INFORMATION TECHNOLOGY AND COMMUNICATION AND THE KNOWLEDGE MANAGEMENT AS SUPPORT TO THE MANAGEMENT OF COMMUNICATIONS IN PROJECTS}

\author{
Greicy Kelli Spanhol ${ }^{1}$; Neri dos Santos ${ }^{2}$ \\ ${ }^{1}$ Universidade Federal de Santa Catarina - UFSC - Florianópolis - Brasil \\ greicy@egc.ufsc.br \\ ${ }^{2}$ Universidade Federal de Santa Catarina - UFSC - Florianópolis - Brasil \\ neri@egc.ufsc.br
}

\begin{abstract}
Resumo
Este artigo objetiva apresentar como as Tecnologias da Informação e Comunicação (TICs) e as Técnicas da Gestão do Conhecimento (GC) podem auxiliar no gerenciamento das comunicações em projetos. A partir de uma revisão de literatura pode-se verificar diferentes bases teóricas $e$ conceituais do tema. Assim, evidencia-se que com o uso convergente das TICs e das Técnicas de $G C$, ofluxo informacional de um projeto é otimizado, devido ao fato, de estas proporcionarem uma base para o compartilhamento das informações e dos conhecimentos de forma segura $e$ organizada.
\end{abstract}

Palavras-chave: Gerenciamento das Comunicações em Projetos; Tecnologias da Informação e Comunicação; Gestão do Conhecimento.

\section{Introdução}

Para manterem-se no mercado cada vez mais competitivo, as empresas vêm adotando a gestão do conhecimento e a inovação como principais estratégias. Seguindo a definição de Nonaka e Takeuchi (1997, p. 12), a gestão do conhecimento é "a capacidade que a empresa tem de criar conhecimento, disseminá-lo na organização e incorporá-lo a produtos, serviços e sistemas". Para Gattoni (2004), os processos de criação, registro e transferência de conhecimentos, que são constituintes da gestão do conhecimento, possibilitam as empresas criar e lançar produtos e serviços com ciclos de vida cada vez mais reduzidos, proporcionando assim, a inovação dentro das organizações. 
$\mathrm{O}$ autor ainda coloca que as inovações precisam ser integradas à rotina empresarial, e a melhor forma de isto acontecer é por meio da elaboração e execução de projetos. Os projetos são uma excelente opção para se implementar mudanças, pois atendem a um objetivo com requisitos específicos, considerando ainda aspectos como restrições de tempo e custo, recursos disponíveis e a qualidade que se deseja alcançar.

O Guia PMBOK® (2004, p. 5) define projeto como “um esforço temporário empreendido para criar um produto, serviço ou resultado exclusivo". Sendo que para sua execução se faz necessário o gerenciamento do mesmo. Uma área do gerenciamento de projeto importante é a comunicação, pois conforme Nascimento e Santos (2003, p. 1), o desempenho de um projeto "pode ser afetado pela falta de tratamento do fluxo de informações de seus processos", assim, a comunicação inadequada pode gerar retrabalhos, indefinições do caminho a ser seguido, problemas na qualidade e nas especificações do produto, entre outros. A comunicação no desenvolvimento de projetos é importante, principalmente por eles serem realizados por equipes. Em geral, as equipes necessitam de informações sobre as suas funções e o andamento das atividades para que, deste modo, possam compreender como executar as tarefas e cumprir os objetivos do projeto.

Para Beber et al (2007) o gerenciamento das comunicações é imprescindível na execução de todas as etapas do projeto, pois este objetiva coletar, distribuir, armazenar e recuperar todas as informações, de forma a auxiliar o fluxo destas ao longo do ciclo do projeto.

E para gerenciar o fluxo informacional de um projeto, pode-se criar meios e utilizar ferramentas e sistemas para formatação, registro e disseminação do conhecimento. Assim, as TICs e as Técnicas de GC aparecem como apoio principal desta etapa, pois permitem o compartilhamento das informações, de maneira clara e objetiva, entre todos os interessados e participantes do projeto.

Nesse sentido, a partir de uma revisão de literatura, procurou-se evidenciar como o fluxo informacional de um projeto pode ser otimizado, com o uso convergente das TICs e das Técnicas de Gestão do Conhecimento.

\section{Gerenciamento de Projetos}

\subsection{Guia PMBOK®}

O PMBOK® Guide ${ }^{1}$ - traduzido para português como Guia PMBOK - Um guia do conjunto de conhecimentos em gerenciamento de projetos - foi desenvolvido pelo $\mathrm{PMI}^{2}$ e desde a sua publicação tem sido utilizado como referência internacional para o gerenciamento de projetos.

\footnotetext{
${ }^{1}$ Project Management Body of Knowledge Guide.
} 
O PMBOK ${ }^{\circledR}$ tem como objetivo principal "identificar o subconjunto do Conjunto de conhecimentos em gerenciamento de projetos que é amplamente reconhecido como boa prática". Ele inclui as "práticas tradicionais comprovadas amplamente aplicadas, além de práticas inovadoras" para que o gerente possa alcançar o sucesso na execução dos projetos. (Guia PMBOK®, p. 3, 2004).

O guia esta estruturado em 3 sessões, conforme quadro 1, abaixo:

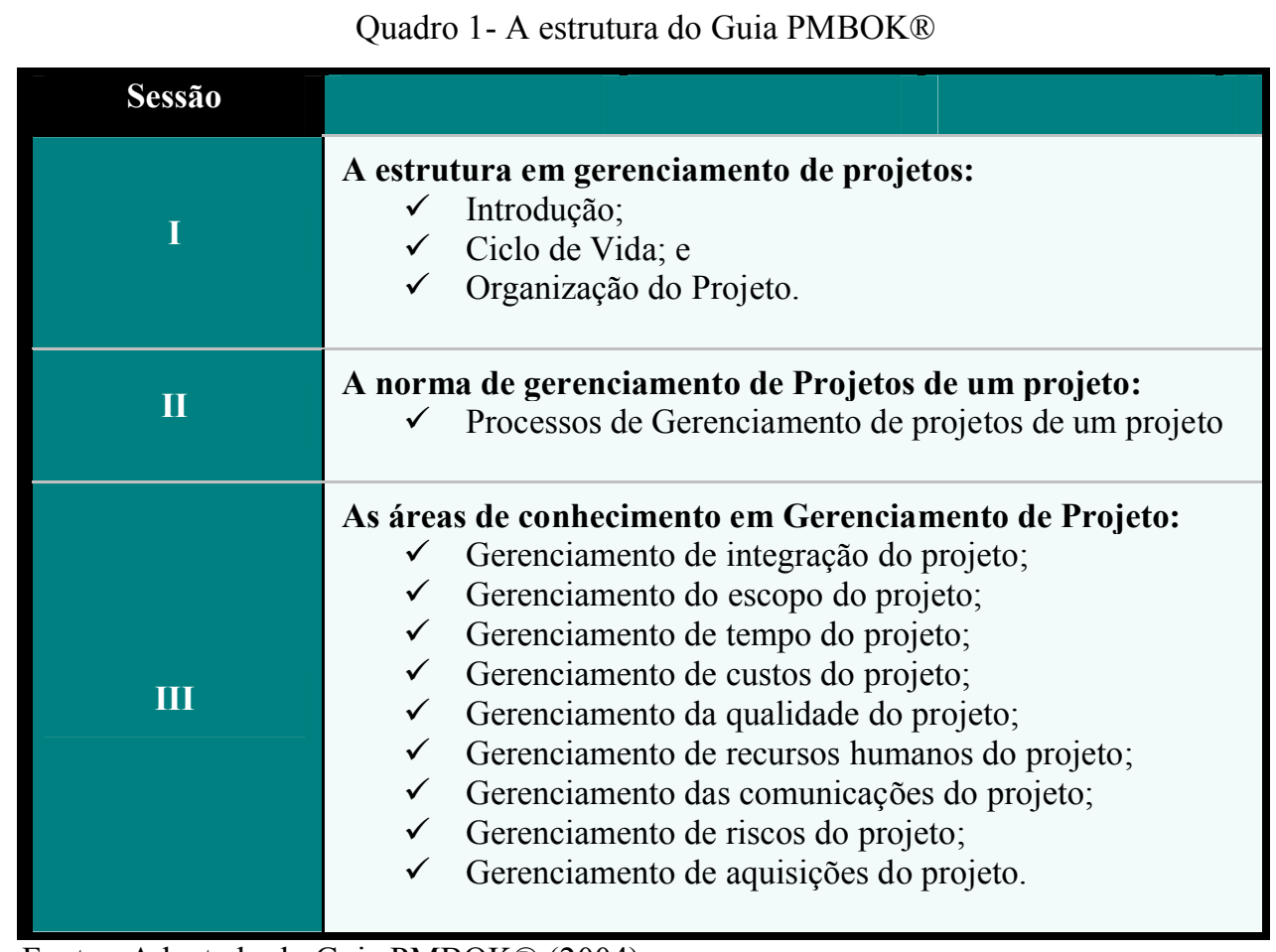

Fonte - Adaptado do Guia PMBOK® (2004)

A Sessão I é direcionada ao entendimento do que é projeto e gerenciamento de projeto (GP), o seu ciclo de vida e a sua organização, bem como elucida a visão geral do Guia.

A Sessão II descreve os processos que compõem os projetos e o seu gerenciamento, além de descrever a natureza multidimensional destes. Os processos são apresentados em 5 grupos: Processos de Inicialização (define e autoriza o projeto); Processos de Planejamento (define os objetivos e planeja a ação); Processos de Execução (integra pessoas e recursos na realização do plano do projeto); Processos de Monitoramento e Controle (monitora o progresso e identifica variações do projeto visando atingir os objetivos planejados); e Processos de Encerramento (formaliza a aceitação do produto, serviço ou resultado final). (PMBOK®, 2004).

A Sessão III se refere às áreas de conhecimento em gerenciamento de projeto, sendo descritos os processos e as atividades que envolvem o mesmo.

\footnotetext{
${ }^{2}$ O PMI - Project Management Institute - publicou a $1^{\mathrm{a}}$. edição do PMBOK em 1987, sendo este revisado e publicado em sua $2^{\mathrm{a}}$. edição no ano 2000. Após contribuições de leitores e profissionais da área, foi publicado a $3^{\mathrm{a}}$. edição em 2004.
} 


\section{2. Áreas de conhecimento em gerenciamento de projeto}

O PMBOK® (2004) identifica 9 áreas do conhecimento para compor o universo do gerenciamento de projetos. Estas áreas são compostas por 44 processos organizados nos 5 grupos de GP acima citados.

A área de gerenciamento de integração do projeto descreve os processos e atividades que o integram; o gerenciamento do escopo envolve a verificação de que o projeto atende todo o trabalho necessário para atingir o objetivo final; o gerenciamento do tempo se refere à questão de cumprimento de prazo; o gerenciamento de custos diz respeito ao plano, estimativa, orçamento e controle de valores financeiros; o gerenciamento da qualidade se preocupa em garantir se o projeto atingirá o nível qualidade esperado; o gerenciamento de recursos humanos organiza e gerencia a equipe de execução; o gerenciamento das comunicações responde pela geração, coleta, disseminação e armazenamento das informações do projeto; o gerenciamento de riscos objetiva aumentar a probabilidade de sucessos e diminuir os possíveis insucessos durante a realização; e, o gerenciamento de aquisições atende as questões de compras e contratos do projeto.

Estas áreas reúnem as 'boas práticas'3 de GP. O PMBOK® (2004) dedica um capítulo para cada uma delas, porém, devido à limitação do tema, este artigo abordará somente o capítulo 10 do guia, que é destinado especificamente ao gerenciamento das comunicações do projeto.

\subsection{Gerenciamento das Comunicações do Projeto}

O Gerenciamento das comunicações é responsável pelo fluxo informacional do projeto, pois este constitui, executa, acompanha e controla as informações durante todo ciclo de vida do mesmo. Segundo Chaves et al. (p. 13, 2006) a área de comunicações "é, por excelência, um elemento de apoio fundamental para o acompanhamento de todas as outras áreas de gerenciamento", já que estas necessitam da obtenção, acompanhamento e emissão das informações para todos os interessados e participantes do projeto.

Chaves et al. (p.29, 2006), afirmam que uma pesquisa feita para o Construction Industry Institute $^{4}$ (CII) dos Estados Unidos, "concluiu que a realização de projetos bem-sucedidos está diretamente ligada à boa comunicação". Assim, com o objetivo de garantir a 'boa comunicação', é

\footnotetext{
${ }^{3}$ O PMBOK ® (2004) apresenta 'boas práticas' como sendo um acordo geral das aplicações de habilidades, técnicas e ferramentas de gerenciamento que propiciem o sucesso do projeto.

${ }^{4}$ O Instituto de Construção Civil tem sede na Universidade do Texas e foi criado em 1983 para melhorar os projetos de construção e os processos de investimento de capital na indústria da construção civil. È formado por proprietários, empresas/construtoras, fornecedores e acadêmicos.
} 
preciso garantir a eficiência e eficácia de cada um dos processos apresentados no quadro 2, empregando técnicas e ferramentas que potencializarão cada uma das etapas de execução da comunicação do projeto. Segundo o Guia PMBOK® (2004) o gerenciamento das comunicações é composto pelos seguintes processos:

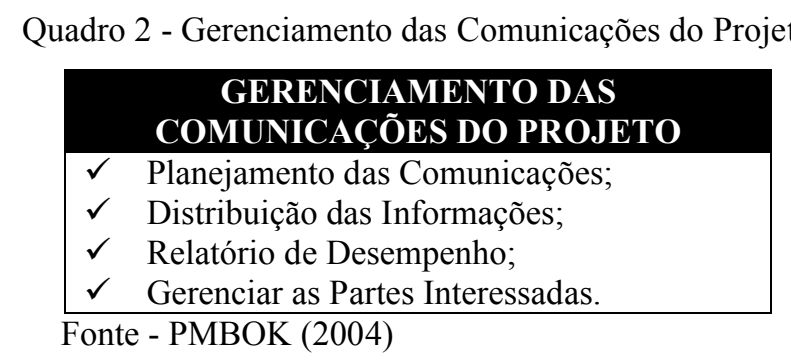

O Planejamento das comunicações determina as informações e comunicações necessárias a cada parte interessada do projeto; a Distribuição das Informações é responsável pela disponibilização das mesmas; o Relatório de Desempenho permite a captação dos dados de linha de base e a disseminação das informações sobre o desempenho às partes interessadas; e o Gerenciamento das partes interessadas gerencia a comunicação com intuito de atender as necessidades das mesmas e assim, resolver possíveis problemas.

\section{As TICs Aplicadas no Gerenciamento das Comunicações do Projeto}

Um dos maiores desafios da comunicação em um projeto está na manutenção das informações, pois coletar, sistematizar e disseminar as informações não é um trabalho simples. E para dar suporte a esta tarefa complexa, são muitas as possibilidades de ferramentas que podem ser utilizadas. O quadro 3, apresentado na página seguinte, elucida as técnicas e ferramentas que podem ser aplicadas em cada um dos processos acima citados. Neste contexto, os processos e as TICs aparecem como base para a comunicação em projetos, pois segundo Chaves et al (p. 58, 2006) estas “fornecem os meios técnicos (ferramentas) pelos quais a informação é distribuída, o progresso é reportado e o feedback é solicitado". Ou seja, o uso destas, amplia a possibilidade de êxito do projeto.

As TICs que, segundo Arruda (2007), são um conjunto de conhecimentos, refletidos em equipamentos, programas e ferramentas, para a criação, registro, armazenamento e difusão de conteúdos informacionais, proporcionam maior flexibilidade para a comunicação, uma vez que, a comunicação por meios eletrônicos ultrapassa barreiras como espaço e tempo, bem como permite a troca de um grande volume de informações de maneira rápida e precisa. 
Quadro 3 - Processos, Técnicas e Ferramentas do Gerenciamento das Comunicações do Projeto

\begin{tabular}{|c|c|c|}
\hline Processos & \multicolumn{2}{|r|}{ Técnicas e Ferramentas } \\
\hline \multirow{2}{*}{$\begin{array}{l}\text { Planejamento } \\
\quad \text { das } \\
\text { comunicações }\end{array}$} & $\begin{array}{l}\text { Análise dos } \\
\text { Requisitos }\end{array}$ & $\begin{array}{l}\text { Organogramas, disciplinas, departamentos, áreas de especialização } \\
\text { dos envolvidos no projeto, informações entre as partes interessadas } \\
\text { e outros. }\end{array}$ \\
\hline & $\begin{array}{l}\text { Tecnologias das } \\
\text { Comunicações }\end{array}$ & $\begin{array}{l}\text { Metodologias usadas para transferir informação. Fatores de } \\
\text { tecnologia que afetam o projeto: urgência da necessidade de } \\
\text { informação, disponibilidade de tecnologia, formação pessoal, } \\
\text { duração e ambiente do projeto. }\end{array}$ \\
\hline \multirow{4}{*}{$\begin{array}{l}\text { Distribuição das } \\
\text { Informações }\end{array}$} & $\begin{array}{l}\text { Habilidades de } \\
\text { Comunicação }\end{array}$ & $\begin{array}{l}\text { Interna: (dentro do projeto) e externa: (o cliente, os meios de } \\
\text { comunicação, o público). } \\
\text { Formal: (relatórios, briefings) e informais (memorandos, conversas } \\
\text { para fins específicos). } \\
\text { Vertical: (para cima e para baixo na organização) e horizontal } \\
\text { (entre os pares). }\end{array}$ \\
\hline & $\begin{array}{l}\text { Sistemas de } \\
\text { Coleta e } \\
\text { recuperação de } \\
\text { informações } \\
\end{array}$ & $\begin{array}{l}\text { Sistemas manuais de arquivamento, bancos de dados eletrônicos, } \\
\text { software de gerenciamento de projetos, sistemas que possibilitam } \\
\text { o acesso à documentação técnica (desenhos de engenharia, } \\
\text { especificações de design, planos de testes). }\end{array}$ \\
\hline & $\begin{array}{l}\text { Métodos de } \\
\text { Distribuição das } \\
\text { Informações }\end{array}$ & $\begin{array}{l}\text { * Reuniões do projeto, distribuição de cópias impressas de } \\
\text { documentos, sistemas manuais de arquivamento e banco de dados } \\
\text { eletrônicos com acesso compartilhado; } \\
\text { * Ferramentas para conferências e comunicação eletrônica (e-mail, } \\
\text { fax, correio de voz, telefone, áudio e videoconferências e } \\
\text { publicações na internet). }\end{array}$ \\
\hline & $\begin{array}{l}\text { Processo de } \\
\text { lições aprendidas }\end{array}$ & $\begin{array}{l}\text { * Base de dados de lições aprendidas, entradas do sistema de } \\
\text { gerenciamento do conhecimento; } \\
\text { * Políticas, procedimentos e processos corporativos atualizados; } \\
\text { * Habilidades de negócios aperfeiçoadas; } \\
\text { * Melhorias gerais nos serviços e produtos; } \\
\text { * Atualização do plano de gerenciamento de riscos. }\end{array}$ \\
\hline \multirow{5}{*}{$\begin{array}{l}\text { Relatório de } \\
\text { Desempenho }\end{array}$} & $\begin{array}{l}\text { Ferramentas de } \\
\text { apresentações de } \\
\text { informações } \\
\end{array}$ & $\begin{array}{l}\text { Pacotes de software com relatórios de tabelas, análises de } \\
\text { planilhas, gráficos. }\end{array}$ \\
\hline & $\begin{array}{c}\text { Coleta e } \\
\text { compilação das } \\
\text { informações } \\
\text { sobre o } \\
\text { desempenho } \\
\end{array}$ & $\begin{array}{l}\text { Sistemas de arquivamento manual, bancos de dados eletrônicos, } \\
\text { software de gerenciamento de projetos, sistemas que possibilitam } \\
\text { o acesso a documentação técnica (desenhos de engenharia, } \\
\text { especificações de design, planos de testes). }\end{array}$ \\
\hline & \begin{tabular}{c|}
$\begin{array}{c}\text { Reuniões de } \\
\text { avaliação do } \\
\text { andamento }\end{array}$ \\
\end{tabular} & São realizadas com freqüências diferentes e em níveis diversos. \\
\hline & \begin{tabular}{c|} 
Sistemas de \\
relatórios de horas
\end{tabular} & Registram e fornecem as horas gastas no projeto. \\
\hline & $\begin{array}{c}\text { Sistemas de } \\
\text { relatórios de } \\
\text { custos }\end{array}$ & Registram e fornecem os custos gastos no projeto. \\
\hline \multirow{2}{*}{$\begin{array}{l}\text { Gerenciar as } \\
\text { partes } \\
\text { interessadas }\end{array}$} & $\begin{array}{l}\text { Métodos de } \\
\text { comunicação }\end{array}$ & $\begin{array}{l}\text { Reuniões presenciais, telefonemas, e-mails, e outras ferramentas } \\
\text { úteis para trocar informações e estabelecer contatos. }\end{array}$ \\
\hline & $\begin{array}{c}\text { Registros de } \\
\text { problemas }\end{array}$ & Usados para documentar e monitorar a resolução do problema. \\
\hline
\end{tabular}

Fonte - Adaptado do Guia PMBOK® (2004)

Para Chaves et al. (p. 59, 2006), as principais ferramentas eletrônicas utilizadas na comunicação em projetos são: Softwares de GP; Websites; E-mail; Ferramentas Case; Repositórios Centrais; Bancos de dados de discussão; Sistemas de Groupware; Sistemas de agendamento e programação; Tele e videoconferência. Porém, os autores ainda afirmam que para implantar as 
ferramentas eletrônicas, antes é necessário identificar o tipo de documentação e os processos a serem empregados na comunicação do projeto, sendo estes:

- Ad hoc: conforme demanda e sem formatação específica, cada integrante da equipe pode definir a formatação do documento;

- Centralizado: documentação padronizada e níveis de aparência estruturados;

- Colaborativo: processo voltado ao trabalho em equipe com interdependências entre das atividades.

A partir de definidos os processos e a forma de documentação, as ferramentas a serem utilizadas, podem ser:

a) Softwares de Gerenciamento de Projetos: fazem o controle dos projetos, e acompanham as atividades, principalmente os itens de cronograma e de custos do mesmo. Atende ainda questões de recursos humanos e materiais, gestão de riscos e lições aprendidas. Especificamente na comunicação podem auxiliar no suporte a documentação de todas as áreas do conhecimento, nos avisos de prazos e tarefas para a equipe, bem como na representação e criação de dados e estatísticas do projeto. Estes softwares atendem os Métodos de Distribuição das Informações, o Processo de lições aprendidas, as Ferramentas de apresentações de informações, os Sistemas de relatórios de horas e custos e os Registros de problemas, que o PMBOK $®$ cita como ferramentas para o gerenciamento das comunicações do projeto.

b) Gerenciamento eletrônico de documentos (GED): Conjunto de tecnologias para organizar e gerenciar documentos em formato digital. As mídias podem ser: imagem, microfilme, áudio, vídeo, arquivos criados de forma digital, documentos a priori em papel que foram digitalizados, etc. Segundo Souza (p.64, 2002) "o GED objetiva gerenciar o ciclo de vida das informações desde sua criação até o seu arquivamento". Chaves et al. (p. 71-74, 2006) afirmam que existem cinco etapas de administração de documentos, sendo estas:

- Gerenciamento corporativo de relatórios: Tecnologia responsável por armazenar e indexar dados gerados eletronicamente;

- Gerenciamento de imagens e documentos: Processo de captação, armazenamento e busca de documentos;

- Processamento de Formulários: Tecnologia utilizada para converter um formulário digitalizado;

- Gerenciamento de documentos digitais: Administra documentos criados eletronicamente.

Para os autores, "sistemas desse tipo são cruciais para a manutenção das bases de informação e conhecimento dos projetos de uma empresa, gerando conteúdo necessário para a 
gestão do conhecimento". Assim, os sistemas de GED podem auxiliar o gerenciamento das comunicações em projetos, tornando-o mais eficiente e eficaz, pois são capazes de categorizar documentos, gerar tabelas de temporalidade, disponibilizar documentos de forma ordenada, controlar níveis de segurança, etc.

c) Sistemas de recuperação da informação: Devido à capacidade atual de armazenamento de documentos eletrônicos, procurar informações específicas dentro destes sistemas, caso estes não estejam organizados com palavras-chave, pode muitas vezes ser complexo. Desta forma, os sistemas de consulta que utilizam recursos queries, tornam esta tarefa mais fácil e ágil, bem como fornecem um ambiente seguro e consistente para o armazenamento de informações. Chaves et al (2006) afirmam que no planejamento das comunicações, o gerente do projeto deve apontar as mídias a serem utilizadas, temporalidade e padronização dos documentos, níveis de acesso, entre outros, para que deste modo, seja otimizada a recuperação das informações do projeto.

d) Áudio, vídeo e Teleconferências: Estes recursos eliminam a distância física entre os participantes do projeto. Segundo Spanhol (1999) a Videoconferência é um sistema de comunicação composto de hardware e software que possibilita a comunicação de áudio e vídeo simultânea e permite a interação entre os usuários independendo da localização geográfica. Para Santos (1998), o uso da videoconferência apresenta uma série de vantagens: economia de tempo; economia de recursos; visualização e alteração pelos integrantes do diálogo em tempo real; compartilhamento de aplicações e compartilhamento de informações (transferência de arquivos), entre outros.

Para utilização destes recursos podem ser montadas estruturas de videoconferência, ou aproveitar recursos da internet, como: MSN Messenger, GTalk, Yahoo Messenger, etc., para suporte a transmissão de áudio e vídeo. A escolha do meio de comunicação de áudio, vídeo e teleconferência dependerá dos recursos que a empresa possui ou mesmo no nível de investimento que a organização que aplicar nestes recursos.

e) Ferramentas de Apoio WEB: Souza (2002, p. 53-54) apresenta as ferramentas de apoio separadas em Internet e Intranet. $\mathrm{O}$ autor afirma que a internet auxilia "nas transmissões de informações, na integração de profissionais e na divulgação de seus produtos e sua imagem institucional" e a Intranet dentro do projeto "traz toda uma tecnologia que alavancará processos mais competitivos". Em uma organização esta gera a integração entre os profissionais e traz o ambiente virtual para promover as relações.

As Principais ferramentas da internet são: Navegadores: (Browsers), Sites de Conteúdo e Sites de Busca. E os principais meios de comunicação via intranet são: Correio eletrônico; BatePapo (Chats); Grupos e Listas de discussão; e FTP $^{5}$ (File Transfer Protocol). Para Chaves et al. (2002), com as aplicações WEB e com os ambientes colaborativos a equipe do projeto pode: enviar

\footnotetext{
${ }^{5}$ Ferramenta para transferência de arquivos entre um ambiente virtual e outro.
} 
e receber e-mails com conteúdos, informações e documentos do projeto, criar fóruns de discussão, conversar on line por meio de chats, compartilhar agendas de reuniões, fazer ligações utilizando VOIP $^{6}$ sem custos adicionais para a organização, usar Workflows $^{7}$, entre outras inúmeras facilidades, contribuindo desta forma, na disseminação das informações do projeto.

f) Ambientes Colaborativos (Intranet e Extranet): Os softwares para trabalho em grupo também são utilizados no gerenciamento das comunicações em projeto. Estes softwares são chamados de Groupware. Hills (1997) os define como "uma ferramenta que ajuda as pessoas a trabalharem juntas com mais facilidade e eficiência, permitindo que se comuniquem, coordenem e colaborem" entre si. Esta afirma ainda que o Groupware possui três características importantes para o gerenciamento da comunicações em projetos:

- Permite que a equipe compartilhe informações;

- Admite que as atividades individuais sejam coordenadas com as atividades dos demais integrantes da equipe; e

- Auxilia no trabalho integrado das pessoas.

Para Naveiro e Valle (1999) o Groupware pode ser definido como "o uso apropriado e integrado de um conjunto de ferramentas e de tecnologias da informação e comunicações de modo a desenvolver o networking interno e externo nas organizações”. Assim, o Groupware se apresenta como mais um meio para a equipe do projeto comunicar, compartilhar e transferir conhecimento.

\section{Gestão do Conhecimento e o Gerenciamento das Comunicações em Projetos}

Gestão do Conhecimento (GC) é um conceito difícil de ser definido com precisão e simplicidade. Todavia, este artigo objetiva apresentar uma série de tentativas de definição, em uma perspectiva de convergência com o gerenciamento das comunicações em projetos.

O Yankee Group $^{8}$ diz que a gestão do conhecimento consiste em estabelecer contatos eficazes entre aqueles que sabem e aqueles que têm necessidade de saber, e de converter o conhecimento pessoal em conhecimento organizacional.

Segundo Ann Macintosh (1996) a GC não trata apenas de gerir ativos de conhecimento, mas também da gestão dos processos que atuam sobre estes ativos. Estes processos incluem: desenvolver, preservar, utilizar e compartilhar conhecimento. Por isso, gestão do conhecimento envolve identificação e análise dos ativos de conhecimento disponíveis, e desejáveis, além dos

\footnotetext{
${ }^{6}$ Voz sobre IP, transmissão de voz suportada por rede de dados.

${ }^{7}$ Parte da "automação total ou parcial de um processo de negócio, durante a qual documentos, informações e tarefas são passadas entre os participantes do processo" (WfMC, 2006).

${ }^{8}$ Grupo de Especialistas em Conectividade Global. http://www.yankeegroup.com.
} 
processos com eles relacionados. Também envolve o planejamento e o controle das ações para desenvolvê-los (os ativos e os processos), com o intuito de atingir os objetivos da organização ou de um projeto em particular.

Para Falcão e Bresciani Filho (1999, p.162), a Gestão do conhecimento é o "processo pelo qual uma organização consciente e sistematicamente coleta, organiza, compartilha e analisa o seu acervo de conhecimento" para alcançar os seus objetivos.

Nonaka e Takeuchi (1997) definem a GC como a capacidade de uma organização de criar novos conhecimentos, de disseminá-los e de integrá-los a produtos, serviços e sistemas.

Da mesma forma, para Skyrme (1999) a GC é a gestão explícita e metódica dos conhecimentos essenciais e dos processos conexos de: criação, aquisição, organização, difusão, utilização e exploração. Trata-se de transformar os conhecimentos individuais em conhecimentos organizacionais que podem ser amplamente compartilhados dentro da organização e aplicados eficazmente.

Para isso, Terra (2003), afirma que a gestão do conhecimento deve fomentar, interligar e apoiar o aprendizado nas organizações, assim, necessita: promover o acesso das informações aos interessados; incentivar a experimentação e agregar o aprendizado para os trabalhadores; estimular conversas intra e inter-organizacionais entre os grupos estratégicos; e subsidiar oportunidades para as pessoas promovendo a escrita, a reflexão e o ensino.

A definição de GC pode ser melhor entendida ao se reexaminar os conceitos de ativos intangíveis, introduzidos por Sveiby (1997). Segundo este autor, todos os ativos e estruturas organizacionais, sejam elas tangíveis ou intangíveis, são resultantes da atividade humana. De fato, o resultado das ações das pessoas, no meio ambiente, pode ser tangível (cultivar jardins, conduzir um carro, desenvolver um projeto, etc.) ou intangível (ter idéias, estabelecer relacionamentos com outras pessoas, entre outros.).

Nesse sentido, pode-se dizer que as pessoas, no desenvolvimento de um projeto, criam relacionamentos, externos e internos ao mesmo, para expressarem as suas competências e trocarem informações. E como as pessoas têm capacidade de agir numa grande variedade de possíveis situações do projeto, quando elas estão desenvolvendo uma atividade de trabalho, aumentam o seu valor. Por isso, a competência humana é, também, um ativo intangível.

Desta forma, pode-se dizer que são três as famílias de ativos intangíveis que deveriam ser incluídos pela organização no desenvolvimento de um projeto:

- Relacionamentos externos: dizem respeito às relações com os clientes, fornecedores e a imagem da organização junto à sociedade; 
- Relacionamentos internos: dizem respeito aos conceitos, modelos gerenciais, programas de computadores, sistemas administrativos e registros de patentes que fazem parte da organização;

- Competência dos trabalhadores: diz respeito à capacidade de ação das pessoas, dentro das organizações, em situações de projeto distintas.

Sveiby (1997), ainda afirma que a GC é a arte de criar valor alavancando os ativos intangíveis. E para conseguir isso é preciso que os gerentes de projeto visualizem os empreendimentos apenas em termos de conhecimento e fluxos de conhecimento. Esta é uma concepção bem diferente do paradigma da era industrial, porque a empresa da era industrial criava valor a partir de bens materiais, movimentando-os dos fornecedores para a fábrica e dela para os clientes. A agregação de valor se dava pela adição de recursos como energia e mão-de-obra. Os projetos hoje desenvolvidos criam valor não a partir de recursos físicos, mas da inteligência e da competência das pessoas, assim como dos relacionamentos entre elas e seus clientes. Por isso, se faz necessário uma reformatação na gestão dos projetos que focalize mais a comunicação, as relações e os fluxos desses ativos intangíveis.

Assim, a Gestão do Conhecimento deve atender questões como:

- Identificação e mapeamento dos ativos intelectuais ligadas à empresa;

- Geração de novos conhecimentos que ofereçam vantagens competitivas para a organização no mercado; e

- Tornar acessíveis grandes quantidades de informação corporativas, compartilhando as melhores práticas e a tecnologia que torna possível tudo isso - incluindo groupwares e intranets. Este ponto engloba muitas coisas e deveria tornar-se parte integrante da maioria dos negócios.

Deste modo, a gestão do conhecimento e suas técnicas e ferramentas, devem gerar transformações culturais e iniciativas gerenciais com o intuito de obter, cultivar, transferir e renovar o conhecimento que os gerentes de projeto precisam para tomar melhores decisões e com maior rapidez. Sendo que, sem esta base não haverá incentivo suficiente, em todos os níveis da organização, para as pessoas compartilharem e capitalizarem seus ativos de conhecimento.

E para promover estas transfomações e dar suporte à comunicação em projetos, a GC fornece técnicas e instrumentos que podem auxiliar na apreensão e difusão do conhecimento, bem como das informações em projetos. 


\subsection{Técnicas da Gestão do Conhecimento utilizados ao gerenciamento de comunicações de projetos}

São muitos os mecanismos de GC que podem administrar a geração e transferência do conhecimento em projetos. No entanto, devido à delimitação do escopo deste artigo, serão apresentadas algumas das técnicas que tem como base as TICs, ou melhor, que utilizam ferramentas da TIC para automatização dos mecanismos de gestão do conhecimento, sendo estas:

\subsubsection{Bancos de Discussão/Conhecimento}

Cada tema, assunto, tendência do projeto podem ser contemplados e discutidos por meio deste instrumento. É possível também a criação de murais eletrônicos, onde questões pertinentes ao projeto podem ser lançadas para todos os grupos. O objetivo deste seria criar um universo virtual que estimule os colaboradores a compartilhar informações e conhecimento (GATTONI, 2004).

\subsubsection{Transferência de conhecimento por tradição}

Esta pode ocorrer de duas formas: por transferência de informação e por transferência de capacidades. A transferência de informação pode utilizar as TICs para distribuição, pois como já estão codificadas, podem ocorrer de maneira articulada e rápida, possibilitando a disseminação do conhecimento. A outra forma se refere à maneira não articulada, sendo esta dinâmica, lenta e geralmente não codificada, o que acaba impossibilitando a disseminação em grande escala do conhecimento (GATTONI, 2004).

\subsubsection{Repositórios do Conhecimento}

Trata-se do conhecimento explícito estruturado na forma de documentos. Dentro de uma organização, este é importante para a uniformização de conceitos, garantindo desta forma, uma estruturação e integração do conhecimento proveniente de múltiplos projetos, bem como propicia o arranjo e classificação dos conhecimentos conforme padrões estabelecidos pela empresa. Um exemplo de informações para estes repositórios são as lições aprendidas em outros projetos.

Outra forma de repositório do conhecimento está ligada à internet. Davenport e Prusak (p. 159, 1999) afirmam que a "web é ideal para publicar informações em múltiplos tipos de plataformas de computador, para bancos de dados multimídia e para exibir o conhecimento que esteja ligado a outros conhecimentos através de hipertextos". Porém, as informações oriundas da internet podem comprometer a confiabilidade dos dados, assim, é importante buscar informações que estejam publicados on line em artigos científicos, revistas eletrônicas, etc. 


\subsubsection{Cenários e Simulações}

Podem-se criar modelos "de como a empresa deverá reagir, e tomar decisões em função dos contextos apresentados". Este tipo exercício auxilia na 'inteligência corporativa' frente às situações a serem enfrentadas no projeto (GATTONI, 2004, p. 63). Levy (1998 apud GATTONI, 2004) enfatiza o uso de vídeos-games para simulações empresariais, bem como a utilização de realidade virtual, e ferramentas de projeção de cenários, pois estas permitem visualizar situações futuras e os seus impactos no contexto organizacional.

\subsubsection{Comunidade de Prática}

Este é "um dos meios mais importantes para se promover e facilitar a criação e transmissão do conhecimento. O termo comunidades de prática (CdP), situa-se entre os principais conceitos da área de gestão do conhecimento" (FREGONEIS, 2006). Conforme McDermott (2000), as CdP, são agrupamentos de pessoas que compartilham e aprendem conjuntamente, sendo por meio físico ou virtual, com objetivos ou necessidades em comum, podendo ser estas: resolução de problemas, troca de experiências, elaborações de modelos e/ou padrões, construções de técnicas, etc., sempre visando alcançar as melhores práticas. Assim, as pessoas aprendem umas com as outras de forma direta e conjuntamente exploram novos temas. Deste modo, cria-se um fluxo de informações sobre assuntos específicos que potencializam a criação e disseminação dos conhecimentos necessários aos projetos.

Assim, estas técnicas e ferramentas de Gestão do Conhecimento são espaços propícios para o compartilhamento de informações. Pois com a utilização destas, é possível coletar e armazenar sistematicamente o conhecimento adquirido, compartilhando o mesmo por meio de uma memória organizacional e promovendo o surgimento de novos conhecimentos, alavancando, desta forma, o fluxo informacional do projeto, o que propiciará maior robustez a Gerência de Comunicações do mesmo.

\section{Considerações Finais}

Como pode ser evidenciado nesta breve revisão de literatura, o uso das TICs e das técnicas de Gestão do Conhecimento, dinamizam o fluxo informacional do projeto. Pois, estas podem levar as informações onde elas realmente são úteis e disponibilizar no momento necessário, de forma que sejam relevantes, precisas e confiáveis, evitando assim, o retrabalho, clientes insatisfeitos e oportunidades perdidas.

Os projetos são uma grande vantagem para a organização, pois atendem a questão de inovação de forma rápida e consideram as especificidades técnicas, o tempo, o custo e a qualidade que se deseja atingir no produto. Os projetos são compostos por diferentes atividades integradas e devido a isso a maneira que as informações são trocadas entre as equipes de trabalho é de suma 
importância. Ou seja, a comunicação dentro de um projeto é a sua base de entendimento. Desta forma, o fluxo de informações e de conhecimentos em um projeto deve ser ágil, constante e em tempo-real. Neste cenário as TICS e as Técnicas de Gestão do Conhecimento, proporcionam uma pilar para o compartilhamento destas informações e conhecimentos de forma segura e organizada. Assim, a capacidade de disseminar o conhecimento em gerenciamento das comunicações em projetos e de prover o suporte à colaboração, permite transformar uma simples informação em vantagem competitiva para empresa no mercado globalizado atual.

\begin{abstract}
This article aims to present as the Information Technology and Communication (ICT) and Knowledge Management Techniques (KM) can assist in the management of communications in projects. From a review of the literature is possible to check different conceptual and theoretical foundations about the subject. Thus, it was observed that with the convergent use of ICTs and KM Techniques, the informational flow of a project is optimized due to the fact of these provide a basis for sharing information and knowledge in a safe and organized
\end{abstract}

Key-words: Communications in Project Management; Information and Communication Technologies; Knowledge Management.

\title{
Referências
}

ARRUDA, R. D. Reflexões sobre o uso das TIC por professores de programas de Pós-graduação em Educação Ambiental do Brasil e da Espanha, Revista Latino-americana de Tecnología Educativa, 6 (1), 79-96, 2007. Disponível em: http:/campusvirtual.unex.es/cala/editio/. Acesso em: 14/07/08.

BEBER, M. ; SCHEER, S. ; WILLE, Silvio Aurélio de Castro . Uso da tecnologia da informação como auxiliadora da gestão da comunicação em escritórios de arquitetura. In: III Encontro de Tecnologia de Informação e Comunicação na Construção Civil, 2007, Porto Alegre. TIC2007 - integração de Sistemas em Arquitetura, Engenharia e Construção. Porto Alegre : ANTAC, 2007. v. 1. p. 1-10.

CARBONE, P. P.; BRANDÃO, H. P.; LEITE, J. B. D.; VILHENA, R. M. de P. Gestão por Competências e Gestão do Conhecimento. 2. ed. Rio de Janeiro: FGV, 2006.

CHAVES, L. E., ET AL. Gerenciamento da comunicação em projetos. Rio de Janeiro: Editora FGV, 2006.

DAVENPORT, T. H.; PRUSAK, L. Conhecimento empresarial. Rio de Janeiro: Campus, 1998.

FALCÃO, S. D.; BRESCIANI FILHO, E. Gestão do Conhecimento. Revista da III Jornada de Produção Científica dasmUniversidades Católicas do Centro-Oeste, Goiânia, v. 2, set. 1999.

FREGONEIS, Jucelia Geni Pereira. Universidade Federal de Santa Catarina. Programa de Pós-Graduação em Engenharia de Produção. Um modelo de gestão do conhecimento em comunidades de prática para capacitação $e$ assessoramento ao professor na área de informática na educação. Florianópolis, 2006. 149 f. Tese (Doutorado) Universidade Federal de Santa Catarina, Centro Tecnológico. Programa de Pós-Graduação em Engenharia de Produção.

GATTONI, Roberto Luis Capuruçu. Gestão do conhecimento aplicada a prática da gerencia de projetos. Belo Horizonte: C/Arte, 2004.

GIL, Antonio Carlos. Como elaborar projetos de pesquisa. 4.ed. São Paulo: Atlas, 2002.

HILLS, M. Intranet como groupware: estratégias e recursos para aumentar a eficiência e a cooperação em sua empresa com a implementação de uma intranet. São Paulo: Berkeley Brasil, 1997. 
McDEMOTT, Richard. Why information technology inspred but cannot deliver knowledge management. In: Lesse. Knowledge and communities. Woburn: Butterworth-Heinemann, 2000.

MACINTOSH, Ann. Position Paper on Knowledge Asset Management. Artificial Intelligence Applications Institute, University of Edinburgh, Scotland, 1996.

NAVEIRO, R. M.; VALLE, J. A. S. Ambiente colaborativo para o desenvolvimento e gerenciamento de projetos. In: ENEGEP 99, 1999, Rio de Janeiro. Encontro Nacional de Engenharia de Produção. Rio de Janeiro : UFRJ, 1999.

NASCIMENTO, L. A.; SANTOS, E. T. O Fenômeno da Sobrecarga de Informações em Equipes de Projeto. In: Workshop Gestão do Processo de Projeto na Construção de Edifícios, 2003, Belo Horizonte.

NONAKA, I.; TAKEUCHI, H. Criação de conhecimento na empresa. 5. ed. Rio de Janeiro: Campus, 1997.

PROJECT MANAGEMENT INSTITUTE - PMI. Um Guia do ConJunto de Conhecimentos em Gerenciamento de Projetos (Guia PMBOK®). Project Management Institute, Four Campus Boulevard, Newton Square, Pensylvannia, USA, Third Edition, 2004. Tradução oficial de "A Guide to the Project Management Body of Knowledge" (PMBOK® Guide).

SANTOS, Neri dos. Educação à distância e as novas tecnologias de Informação e Aprendizagem. Disponível na Internet: http://www.engenheiro2001.org.br/programas/980201a2.htm. Consultado em 04.08.04.

SKYRME, D., Knowledge Networking: Creating the Collaborative Enterprise. Oxford: Butterworth-Heinemann, 1999.

SOUZA, G. F. de. Proposta de um modelo para gerenciamento das comunicações de projetos para empresas de tecnologia. Dissertação (Mestrado em Engenharia de Produção) - Centro Tecnológico, Universidade Federal de Santa Catarina, Florianópolis, 2002.

SPANHOL, Fernando José. Universidade Federal de Santa Catarina. Estruturas tecnológica e ambiental de sistemas de videoconferência na educação a distância: estudo de caso do Laboratório de Ensino a Distância da UFSC /. Florianópolis, 1999. 121f. Dissertação (Mestrado) - Universidade Federal de Santa Catarina, Centro Tecnológico.

SVEIBY, K. E., A Nova Riqueza das Organizações. Rio de Janeiro: Campus, 1998.

TERRA, José Cláudio Cyrineu. Gestão do Conhecimento e E-learning na prática. Org. José Cláudio Cyrineu Terra. Rio de Janeiro: Elsevier, 2003.

WfMC - The Workflow Management Coalition: Process Thought Leadership ${ }^{\mathrm{TM}}$. Disponível em: http://www.wfmc.org. Acesso em: 20/07/08.

\section{Inserir aqui dados completos de TODOS os autores:}

Nome completo: Greicy Kelli Spanhol

Filiação institucional: Universidade Federal de Santa Catarina

Departamento: Engenharia do Conhecimento

Função ou cargo ocupado: Gerente de Processos do Laboratório de Educação a Distância / Aluna de Mestrado do Programa de Pós-Graduação em Engenharia e Gestão do Conhecimento

Endereço completo para correspondência (bairro, cidade, estado, país e CEP):

Rua Deputado Antonio Edu Vieira, 1020. Bloco B. AP. 303. - Bairro: Pantanal - Florianópolis -

Santa Catarina - Brasil - CEP: 88040-001

Telefones para contato: 48 9977-6999

e-mail:greicy@egc.ufsc.br 
Nome completo: Neri Dos Santos

Filiação institucional: Universidade Federal de Santa Catarina

Departamento: Engenharia do Conhecimento

Função ou cargo ocupado: Chefe de Departamento

Endereço completo para correspondência (bairro, cidade, estado, país e CEP):

Universidade Federal de Santa Catarina - Centro Tecnológico - Departamento de Engenharia do

Conhecimento - Bairro Trindade - Florianópolis - Santa Catarina - Brasil - CEP 88040-970

Telefones para contato: 48 3721-7117

e-mail:neri@egc.ufsc.br

Recebido para publicação em: 10/01/2009

Aceito para publicação em: 09/03/2009 